International Journal on Intelligent Electronic Systems, Vol. 6 No. 1 January 2012

\title{
DESIGN, DEVELOPMENT AND PERFORMANCE ANALYSIS OF SIGNAL CONDITIONING CIRCUIT OF FAST RESPONSE ELECTRONICS FOR EDDYCURRENT FLOWMETER IN PFBR
}

\author{
Poornapushpakala S. ${ }^{1}$, Gomathy C. $^{2}$ \\ ${ }^{1,2}$ Department of Electronics \& Control Engg., Sathyabama University, Chennai, Tamilnadu, India \\ Email: 'poornapushpakalas@gmail.com, ${ }^{2}$ cgomathy@yahoo.co.uk
}

\begin{abstract}
Eddycurrent Flowmeter is used for measuring the sodium flowrate in the outlet of the primary sodium pump of the Prototype Fast Breeder Reactor. Sodium flowrate monitoring is essential for protection of the reactor. Hence fast response electronics is required for processing the Eddycurrent flowmeter signal. The signal conditioning circuit plays a vital role in designing the fast response electronics for Eddycurrent Flowmeter. The previous electronics design has a pre-amplifier, isolation amplifier, low pass filter and precision rectifier. With the existing electronics a response time of 1.5 sec was achieved to detect the changes in flowrate. The major contribution of the delay in the electronics was due to the filter and $A C$ to $D C$ conversion. This work presents the improvements in the design methods of the signal conditioning circuit which has a faster response time. The simulation and experimental results prove that the designed electronics can detect the changes in flowrate with a response time of less than $25 \mathrm{~ms}$.
\end{abstract}

Key Word: Eddycurrent Flowmeter, Response time and Signal conditioning circuit.

\section{INTRODUCTION}

Eddy current Flow Meter (ECFM) was specially designed for measuring sodium flow in the outlet of the fuel sub-assemblies and the primary sodium pump in Prototype Fast Breeder Reactor (PFBR). Deterioration of the properties of permanent magnets and other ferromagnetic parts may seriously worsen the performance of other types of flowmeters like permanent magnet flowmeter, hence ECFM are much suitable for flow measurement in high-temperature liquid metal systems [1,2]. Sodium flow measurement is essential to monitor the pump performance and to protect the reactor against events like one primary pump seizure, one primary pump trip, off site power failure and rupture of pipe joining primary pump to grid plate thus enabling a safe shut down of the reactor $[3,4]$. The ECFM consists of a primary and two secondary coils excited by a constant current source of $200 \mathrm{~mA}$ at a frequency of $400 \mathrm{~Hz}$ [5]. The ECFM was modeled using FEM analysis and various performance tests were done to find the optimum excitation frequency, also the flow characteristics at different temperature [3]. When an ECFM is inserted in the primary sodium pump outlet a voltage is induced in the secondary coils in addition to the transformer voltage corresponding to the flow of sodium. The differential output of the secondary coils is proportional to the sodium velocity $[3,5]$. The existing electronics of the ECFM sensor has a drive unit and a signal processing unit with temperature compensating circuits. The drive unit gives a constant current output at constant frequency, to the primary coil. The signal processing unit consists of pre amplifiers, low pass filters, $A C$ to $D C$ converters for each secondary coil signals $[6,7]$.

\section{DESIGN CRITERIA AND SELECTION OF COMPONENTS}

The objective was to design an electronics system which provides a continuous monitoring of sodium flowrate and detects the changes in flowrate within $100 \mathrm{~ms}$ including the temperature compensation. The design criteria considered was $100 \mathrm{mV}, 400 \mathrm{~Hz}$ signal for each channel and maximum differential output of $45 \mathrm{mV}$ corresponds to $30 \mathrm{~m} / \mathrm{sec}$ of velocity [8]. In this work the delay due to the sensor is not taken in to consideration. The main requirement is to reduce the response time of the electronics excluding the sensor response time. To design a circuit, first selection of proper component based on the specification need to be done. Figure 1.0 represents the block diagram of Signal conditioning circuit for a single channel. 


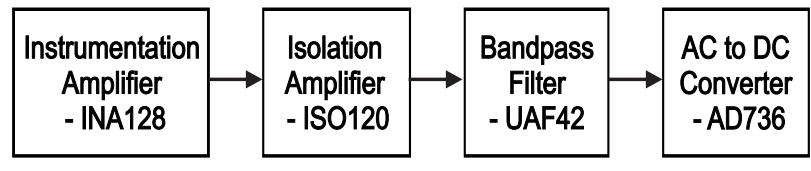

Fig. 1 Block Diagram of Signal conditioning circuit for single channel

\section{A. Instrumentation Amplifier}

Since the signal for each channel ranges from 0 to $100 \mathrm{mV}$, instrumentation amplifier is best suited for pre amplification of such small signal and also to reduce the noise. Comparing various products of instrumentation amplifier and their specifications, INA 128 was chosen for its low voltage drift, high CMRR ratio and only a single external resistor is required for the gain setting. The gain can be set from 1 to 10,000 by external gain setting resistor $(\mathrm{Rg})$ using the gain formula, given by equation (1).

$$
\text { Gain }=\frac{1+50 K \Omega}{R_{g}}
$$

For this application, $R_{g}$ is selected as $5 K \Omega$ which gave a gain of 11 .

\section{B. Isolation Amplifier}

There is need of electrical isolation between the electronics and the sensor, for this purpose an isolation amplifier was introduced after the pre amplification. Initially AD215 was chosen for its low non linearity characteristics and it has a built-in isolated supply. But when error budget analysis was prepared for the isolation amplifiers, ISO120 gave less error than AD215. Thus finally ISO120 was selected as isolation amplifier for the application. The ISO120 is a precision isolation amplifier incorporating a novel duty cycle modulation demodulation technique. The signal is transmitted digitally across a differential capacitive barrier.

\section{Active Filter}

In order to take out the unwanted signal or noise and retain only the original secondary signal a filter is required. Comparing many available active filters, UAF42 was selected for its flexibility to configure any type of filter in the range of 0 to $100 \mathrm{KHz}$. The UAF42 is a universal active filter which can be configured for a wide range of low-pass, high-pass and band-pass filters. For this application a second order Butterworth band pass filter was designed with unity gain. From equation (2) for Bandpass gain $\left(A_{B p}\right)=1$, Gain setting resistor, $R_{G}$ was calculated to be $50 \mathrm{~K} \Omega$. A center frequency of $400 \mathrm{~Hz}$ with a Bandwidth of $100 \mathrm{~Hz}$ was considered for the design calculation. From equation (3) $Q$ was calculated to be 4 . From equation (4) the $Q$ setting resistor $R_{Q}$ was calculated to be $8.3 \mathrm{~K} \Omega$ assuming the external filter resistor $R_{F 1}, R_{F 2}$ to be 400 $\mathrm{K} \Omega$.

$$
\begin{aligned}
& A_{B p}=\frac{R_{4}}{R_{C}} \\
& Q=\frac{f_{m}}{f_{2}-f_{1}}
\end{aligned}
$$
bandwidth

$f_{m}=$ Bandpass mid frequency; $f_{2}-f_{1}=$

$$
Q=\frac{1+\frac{R_{4}\left(R_{G}+R_{Q}\right)}{R_{G} R_{Q}}}{1+\frac{R_{2}}{R_{1}}}\left(\frac{R_{2} R_{F 1} C_{1}}{R_{1} R_{F 2} C_{2}}\right)^{\frac{1}{2}}
$$

\section{D. $A C$ to $D C$ Conversion}

Since the output of signal conditioning circuit has to be given to the microcontroller, the AC signal should be converted in to DC signal. Initially a design was made using precision rectifier and RC Filter. RC filter was tried in both series and parallel combinations. The design has been tested for various combinations of $\mathrm{RC}$ values for $1 \%$ ripple calculated using the formula given by equation (5) and the results were tabulated. With $R$ and $C$ in parallel the response time was better, but the ripples were more than $1 \%$. With $\mathrm{R}$ and $\mathrm{C}$ in series the ripples were within $1 \%$ but the response time was more than $150 \mathrm{~ms}$. Compromise between response time and ripple is not advisable so a challenging design is required.

$$
\text { Ripple }=\frac{1}{4 \sqrt{3} f R C}
$$

A True RMS to DC converter (AD736) has replaced the precision rectifier and $\mathrm{RC}$ filter. The AD736 can compute the rms value of both ac and dc input voltages. The AD736 is capable of computing the average rectified value, absolute value, or true rms value of various types of input signals. $A D 736$ gave 
better result with response time of $4.23 \mathrm{~ms}$ and less than $1 \%$ ripples.

\section{SIMULATION}

After selection of components and design of the signal conditioning circuit, simulation of the same is done on Cadense PSD 14.2 ORCAD software. For simulating the signal conditioning circuit in PSpice the components INA128, ISO120 and UAF42 are available in the cadense library but AD736 is not available in the library. The PSpice model corresponding to AD736 was created with the script using model editor. The model thus created was added in to the PSpice library. The signal conditioning circuit was simulated as shown in Figure 2.0. PSpice simulation output at various output stages of the signal conditioning circuit is shown in figure 3.0. The Signal conditioning circuit simulated in PSpice was tested for various input signals, at a frequency of $400 \mathrm{~Hz}$ and the results were recorded. From Table 1.0 it is observed that the output of instrumentation amplifier, Isolation amplifier and active filter were close to the theoretical value.
Table 1 PSpice simulation results

\begin{tabular}{|c|c|c|c|}
\hline $\begin{array}{c}\text { Input to } \\
\text { Instrumentation } \\
\text { amplifier (V) }\end{array}$ & $\begin{array}{c}\text { Output of } \\
\text { Instrumentation } \\
\text { amplifier (V) }\end{array}$ & $\begin{array}{c}\text { Output } \\
\text { of } \\
\text { Filter } \\
\text { (V) }\end{array}$ & $\begin{array}{c}\text { DC } \\
\text { Output } \\
\text { (V) }\end{array}$ \\
\hline 0.047 & 0.517 & 0.52 & 0.18 \\
\hline 0.066 & 0.726 & 0.73 & 0.25 \\
\hline 0.083 & 0.913 & 0.91 & 0.3 \\
\hline 0.106 & 1.166 & 1.16 & 0.4 \\
\hline 0.137 & 1.507 & 1.5 & 0.5 \\
\hline 0.142 & 1.562 & 1.6 & 0.57 \\
\hline 0.16 & 1.76 & 1.75 & 0.6 \\
\hline 0.246 & 2.706 & 2.8 & 0.99 \\
\hline
\end{tabular}

\section{DEVELOPMENT}

Since the simulated results were satisfactory the printed circuit board design was carried out for the simulated circuit using Altium designer software. With this software the pin configuration of INA128, ISO120, UAF42 and AD736 was made based on their specifications. According to the design all the

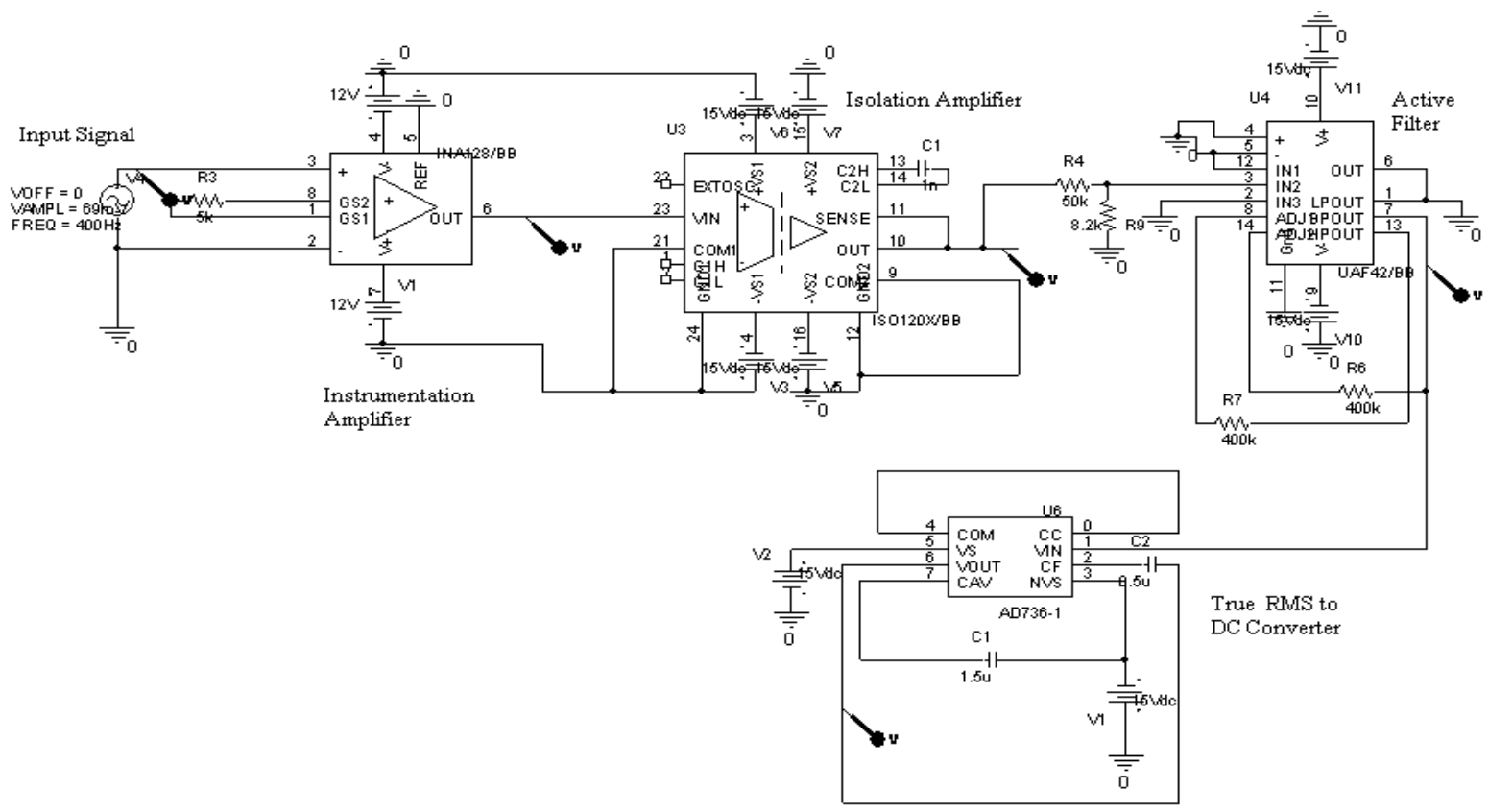

Fig. 2. PSpice simulation of signal conditioning circuit for a single channel. 


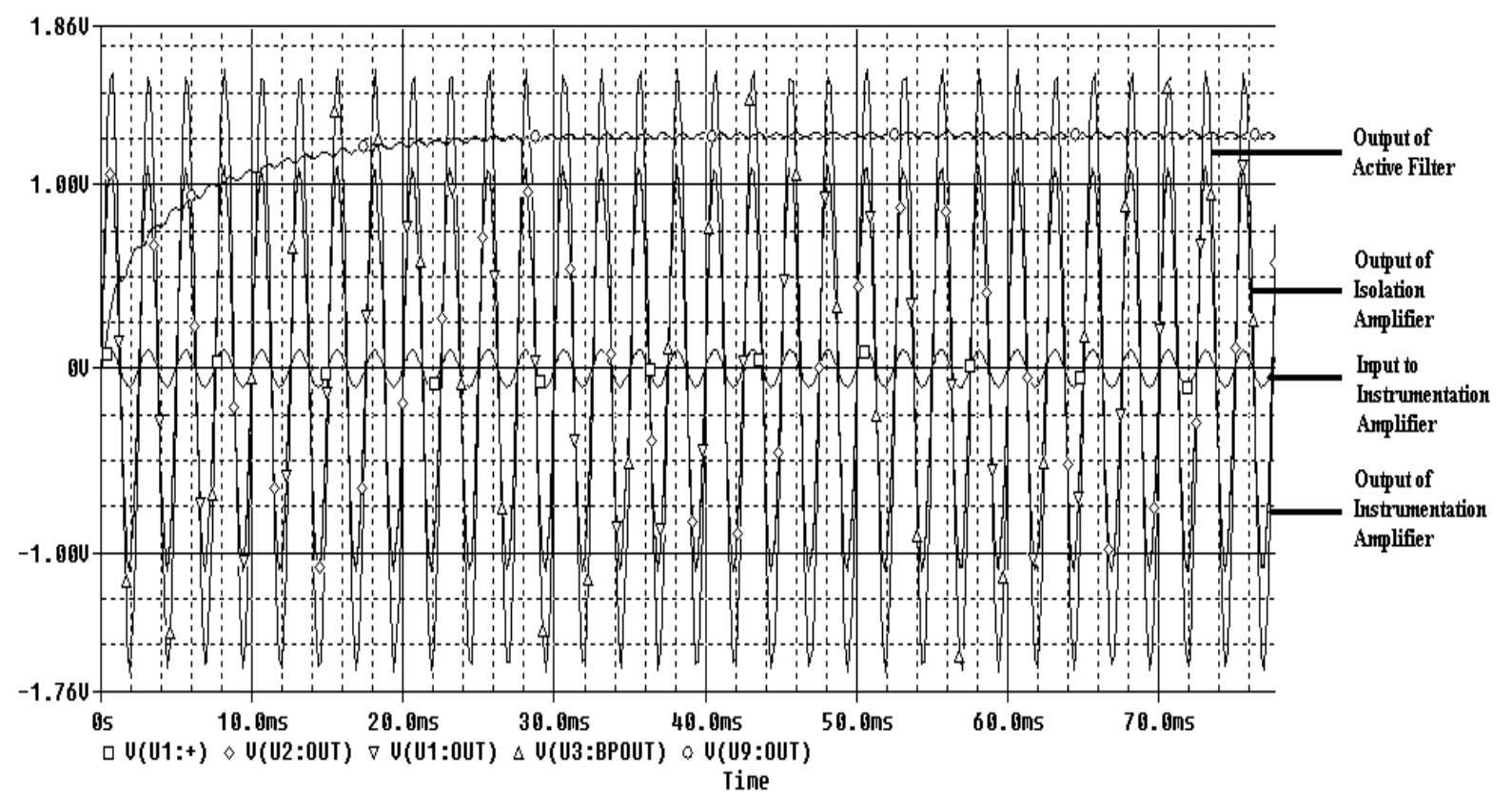

Fig. 3 PSpice simulation output at various stages of Signal Conditioning circuit

components are placed and inter connected. After interconnection, the Printed Circuit board layout was made for the standard Eurocard size $(100 \mathrm{~mm} \mathrm{X} 160$ $\mathrm{mm})$. Inside the layout all the components along with the Eurocard connector are rearranged and routed using two layers. Figure 4.0 shows the signal conditioning circuit developed in Altium designer.

\section{PERFORMANCE TEST}

The performance of the signal conditioning circuit was tested by giving input signal to the Instrumentation

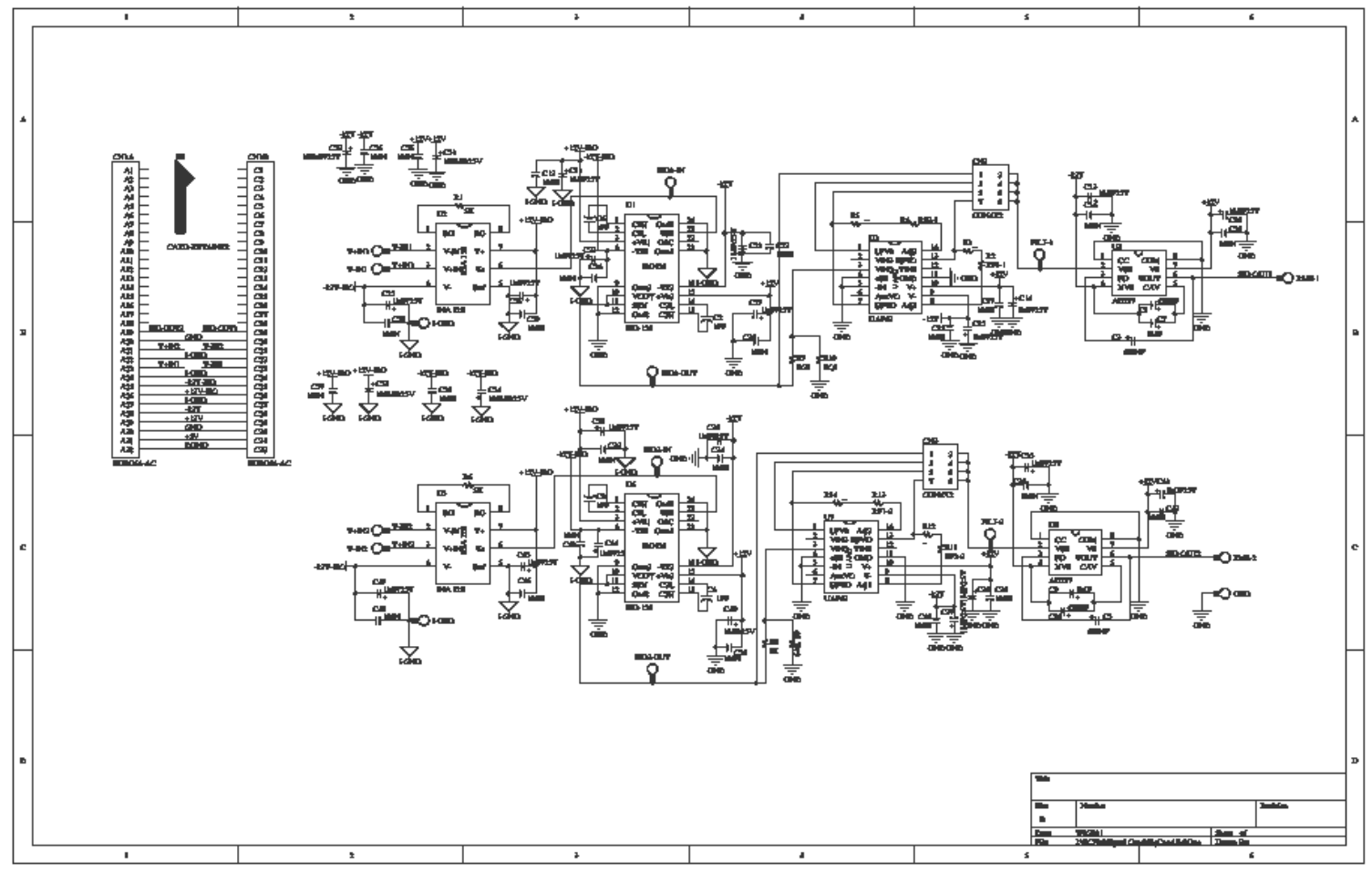

Fig. 4. Signal Conditioning circuit developed Using Altium Designer software 
amplifier. The signal was kept at a constant frequency of $400 \mathrm{~Hz}$. By varying the amplitude of the signal the output at different output stages were recorded. Table 4.0 shows the experimental results of the signal conditioning circuit at various output points. The experimental results of instrumentation amplifier and isolation amplifiers were close to the simulation results. But the experimental output of the filter showed deviation from that of the simulated results. The performance of the Filter was tested by giving constant input voltage of $80 \mathrm{mV}$ at various frequencies and the outputs were recorded. Figure 5.0 shows the Filter gain response for various frequency signals. The main objective of this work is to reduce the response time of the signal conditioning circuit, hence the response time was observed by giving a burst of sinusoidal signal at a frequency of $400 \mathrm{~Hz}$ for a time period of $10 \mathrm{~ms}$ and the signal off time was for $50 \mathrm{~ms}$ and the response time was measured as $5 \mathrm{~ms}$. Figure 6.0 shows the response of the Signal conditioning circuit

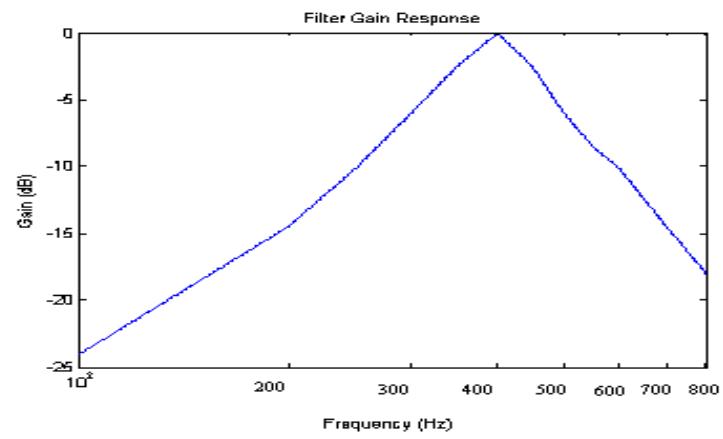

Fig. 5. Shows the filter gain response for various for a burst of signal. Similarly various amplitude changes were introduced in the input signal and the response time was measured. It was observed that the response time on an average comes out to be $15 \mathrm{~ms}$.

\section{Table 2 Experimental results of the Signal} conditioning Circuit

\begin{tabular}{|c|c|c|c|}
\hline $\begin{array}{c}\text { Input to } \\
\text { Instrumentation } \\
\text { amplifier (V) }\end{array}$ & $\begin{array}{c}\text { Output of } \\
\text { Instrumentation } \\
\text { amplifier (V) }\end{array}$ & $\begin{array}{c}\text { Output } \\
\text { of Filter } \\
\text { (V) }\end{array}$ & $\begin{array}{c}\text { DC } \\
\text { Output } \\
\text { (V) }\end{array}$ \\
\hline 0.047 & 0.533 & 0.52 & 0.18 \\
\hline 0.066 & 0.696 & 0.63 & 0.22 \\
\hline 0.083 & 0.844 & 0.81 & 0.28 \\
\hline 0.106 & 1.1 & 1.1 & 0.358 \\
\hline 0.137 & 1.44 & 1.41 & 0.525 \\
\hline 0.142 & 1.5 & 1.5 & 0.543 \\
\hline 0.16 & 1.9 & 1.85 & 0.6 \\
\hline 0.246 & 2.6 & 2.5 & 0.88 \\
\hline
\end{tabular}

\section{RESULTS AND DISCUSSION}

The PSpice simulation results and the experimental results were shown in tabulation 1.0 and 3.0. This indicates that the experimental results were close to the simulation results. Figure 7.0 shows the comparison of Simulation and experimental results of Instrumentation amplifier. Figure 8.0 Experimental and PSpice simulation results of Bandpass Filter. Figure 9.0 shows the comparison of experimental and simulation

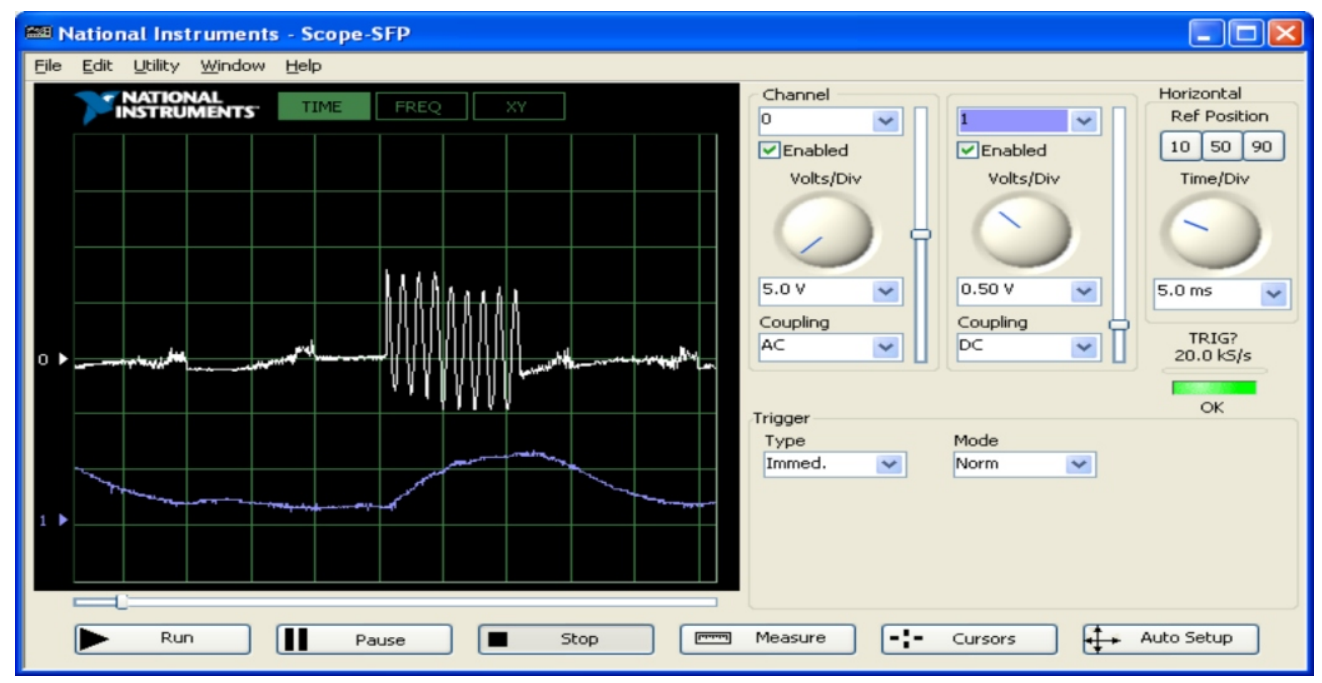

Fig. 6. Response of Signal conditioning circuit for burst of signal 


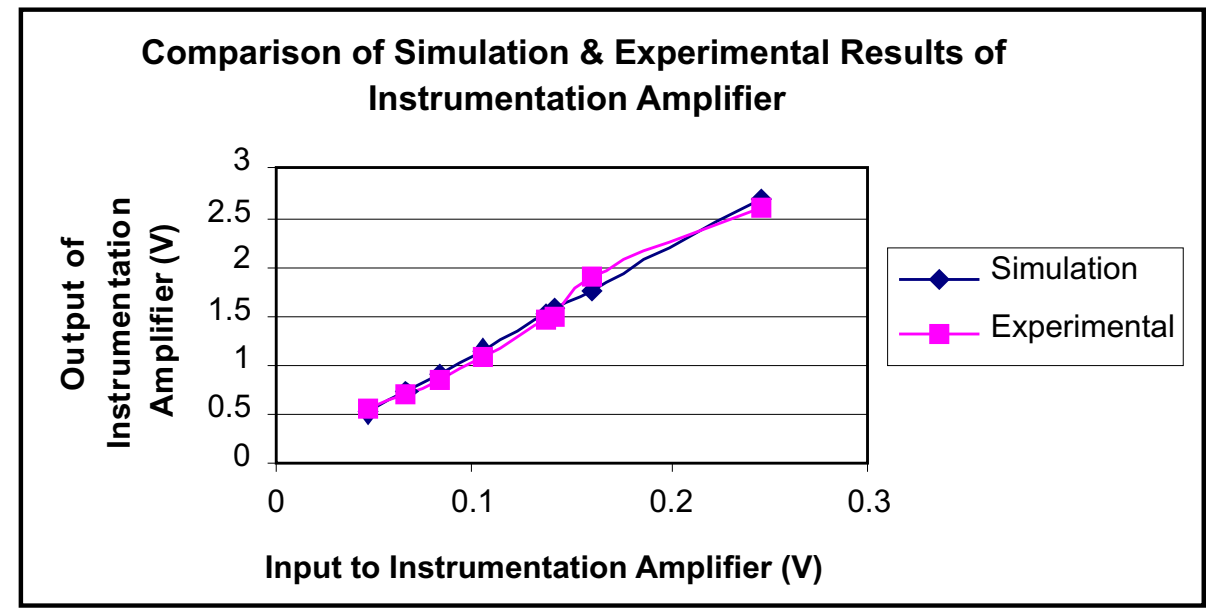

Fig. 7. Experimental and PSpice simulation results of Instrumentation amplifier

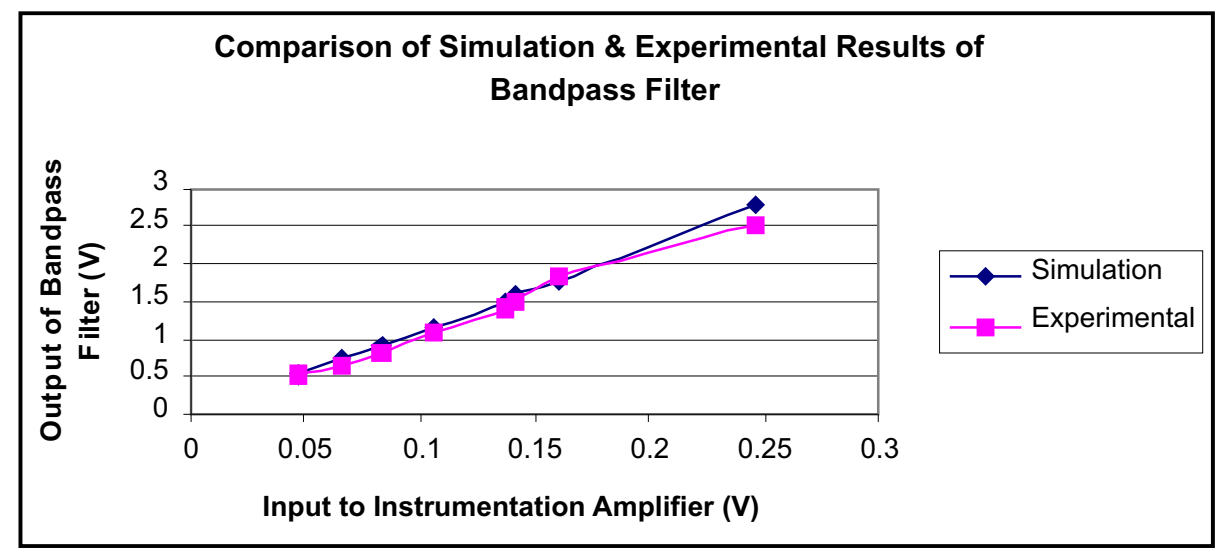

Fig. 8. Experimental and PSpice simulation results of Bandpass Filter

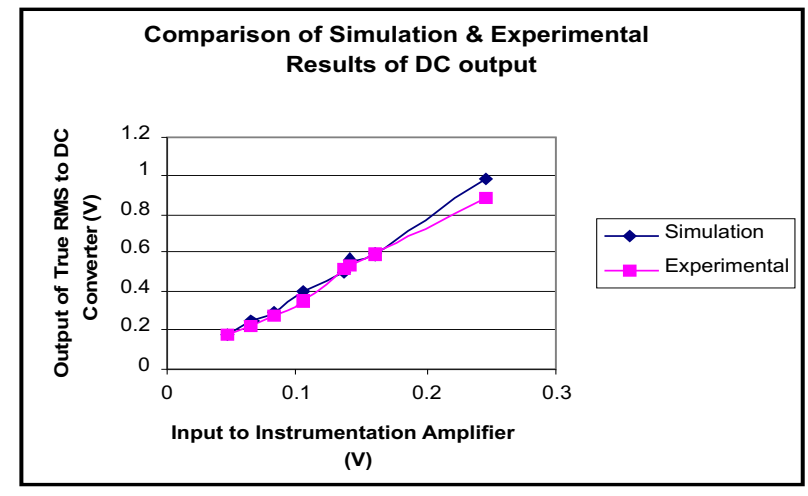

Fig. 9. Experimental and PSpice simulation results of True RMS to DC converter

result of True RMS to DC Converter. The comparison results depicts the experimental results has close agreement with the simulation results. The Signal conditioning circuit was tested for the worst case condition that is for the maximum difference between the two secondary outputs of ECFM, the average rise time of the circuit was less than $25 \mathrm{~ms}$. But the average fall time was around $40 \mathrm{~ms}$ hence the influence on the capacitance of the circuit need to be studied.

\section{CONCLUSION}

The Probe type ECFM is used for the measurement of sodium flow in sub-assemblies and primary pump by pass line in PFBR. The developed signal conditioning circuit is an integrated part of fast response electronics for measuring the flow of sodium from the ECFM sensor output. The output of this circuit has to be given to a microcontroller for processing. The circuit was tested for a various types of generated signal. The Signal conditioning circuit has to be tested for actual ECFM sensor signal for further analysis.

\section{ACKNOWLEDGEMENT}

This work was supported by Indira Gandhi Centre for Atomic Research, Department of Atomic Energy, 
Kalpakkam, India. The Authors are thankful for the support extended by the Director and all the scientists of IGCAR, Kalpakkam.

\section{REFERENCES}

[1] David E. Wiegand - 'Summary of an Analysis of the Eddy current flowmeter':IEEE Transaction on Nuclear Sciences Vol 15, Issue 1 February 1968.

[2] David E. Wiegand \& Charles W. Michels -'Performance tests on an eddy-current flowmeter', IEEE Transactions on Nuclear Science Vol.16, Issue 1, February 1969.

[3] Prashant Sharma, S.K. Dash, B.K. Nashine, S. Suresh Kumar, R. Veerasamy, B. Krishnakumar, P. Kalyanasundaram, G. Vaidyanathan - 'Performance Prediction of Eddy Current Flowmeter for Sodium', Proceedings of the COMSOL Conference 2009 Bangalore.

[4] Prashant Sharma, S. Suresh Kumar, B.K. Nashine, R. Veerasamy, B. Krishnakumar, P. Kalyanasundaram, G. Vaidyanathan - 'Development, computer simulation and performance testing in sodium of an eddy current flowmeter', Annals of Nuclear Energy 37 (2010) 332-338.
[5] R. Veerasamy, C. Asokane, K. Narayanan, R. Dhanasekaran, K. Swaminathan and R. Prabhakar 'Eddy current flowmeter for incore flow measurement in fast reactors', 8th National seminar on Physics Technology of sensors (NSTPS-8) in Feb. 2001 at IGCAR, Kalpakkam.

[6] Veerasamy R., Sureshkumar S., Asokane C., Sivakumar N.S, Padmakumar G., Dash S.K., Sreedhar B.K., Chandramouli S., Gurumoorthi K. and Vaidyanathan G. - 'Eddy Current Flow Sensor Development And Testing For LMFBR Sodium Pumps', 15th International Conference on Nuclear Engineering Nagoya, Japan, April 22-26, 2007, ICONE15-10213.

[7] Poornapushpakala S., Gomathy C., Sylvia J.I, Krishnakumar B., Kalyanasundaram P. - 'An analysis on eddy current flowmeter - a review', Proceedings of the International Conference on Recent Advances in Space Technology Services and Climate Change (RSTSCC), 2010 appearing in IEEE-Xplore

[8] Poornapushpakala S., Gomathy C., Sylvia J.I, Krishnakumar B., Kalyanasundaram P. - 'Design of Fast Response Electronics for Eddy Current Flowmeter', Proceedings of the 7th International Conference on Trends in Industrial Measurements and Automation, January 6-8, 2011. 